$\begin{array}{ll} & \text { Etnográfica } \\ \text { etnográfica } & \text { Revista do Centro em Rede de Investigação em }\end{array}$

Antropologia

vol. $18(2) \mid 2014$

Vol. $18(2)$

\title{
Da investigação por objetivos à antropologia dos processos identitários: um ponto de vista transdisciplinar e integrativo
}

From the research by objectives to an anthropology of identity processes, based in a transdisciplinary and integrative point-of-view

José Gabriel Pereira Bastos

\section{OpenEdition}

\section{Journals}

\section{Edição electrónica}

URL: https://journals.openedition.org/etnografica/3718

DOI: 10.4000/etnografica.3718

ISSN: 2182-2891

\section{Editora}

Centro em Rede de Investigação em Antropologia

\section{Edição impressa}

Data de publição: 1 junho 2014

Paginação: 341-364

ISSN: 0873-6561

\section{Refêrencia eletrónica}

José Gabriel Pereira Bastos, «Da investigação por objetivos à antropologia dos processos identitários: um ponto de vista transdisciplinar e integrativo», Etnográfica [Online], vol. 18 (2) | 2014, posto online no dia 09 julho 2014, consultado o 10 fevereiro 2022. URL: http://journals.openedition.org/etnografica/ 3718 ; DOI: https://doi.org/10.4000/etnografica.3718

\section{(c) (1) \&}

Etnográfica is licensed under a Creative Commons Attribution-NonCommercial 4.0 International License. 


\section{Da investigação por objetivos à antropologia dos processos identitários: um ponto de vista transdisciplinar e integrativo}

\section{José Gabriel Pereira Bastos}

Um percurso científico orientado por objetivos antropológicos deslocou-se da psicologia social para a psicanálise e, posteriormente, para a antropologia social e cultural, com motivações claras: a integração transdisciplinar, a busca da experiência etnográfica, complementar da experiência psicanalítica, a construção de uma abordagem estrutural-dinâmica, pós-racionalista, e a criação de instrumentos de pesquisa a utilizar na investigação de objetos estratégicos selecionados teoricamente (as dinâmicas da interetnicidade e da articulação multidimensional entre representações sociais identitárias, a análise das produções culturais da modernidade, as estratégias de materialização simbólica do inconsciente transcultural). Neste percurso, ensaiámos evidenciar como a articulação da análise teórica, da análise documental, da construção de instrumentos de pesquisa orientados por objetivos, potenciadores do tratamento matemático da informação e de uma articulação heurística com a pesquisa qualitativa, pôde fazer avançar novos conceitos e novas hipóteses sobre a função central dos processos identitários na construção e na transformação sócio-histórica, em aberto, das identidades pessoais, de género, familiares, interétnicas e políticas, entre si articuladas, num sistema-mundo tensionalmente diferenciado, de forma multidimensional, contraditória e instável. Consideramos a antropologia dos processos identitários como a pedra de fecho do edifício inacabado da antropologia social e cultural, permitindo a articulação integrativa das disciplinas que estilhaçam a pesquisa antropológica.

PALAVRAS-CHAVE: análise das produções culturais, análise dos processos identitários, abordagem estrutural-dinâmica, pesquisa por objetivos, criação de instrumentos de pesquisa, teorização integrativa.

From the research by objectives to an anthropology of identity processes, based in a transdisciplinary and integrative point-of-view - A scientific journey oriented by anthropological goals began with social psychology, then delved into psychoanalysis and later cultural and social anthropology, always guided by clear objectives: trans-disciplinary integration; the quest for ethnographic experience as a complement of psychoanalytical experience; the construction of a structural-dynamic, post-rationalist approach; and the creation of research tools to be employed in the exploration of strategic objects, selected via theory (the dynamics of inter-ethnicity and of the multi-dimensional articulation between identity-based social representations, the analysis of the cultural productions of modernity, and strategies of symbolic materialization of the trans-cultural unconscious). On this journey, we attempted to call attention to the ways in which the articulation of 


\begin{abstract}
theoretical analysis, documentary analysis, and the construction of objective-oriented research tools - which enables the mathematical processing of information and a heuristic articulation with qualitative research - made it possible to put forward new concepts and hypotheses regarding the crucial function of identity processes in the open-ended and interconnected socio-historical construction and transformation of personal gender, family, inter-ethnic, and political identities, within a tensionally differentiated world system, in a multidimensional, contradictory, and unstable form. We consider the anthropology of identity processes as the integrative keystone of the unfinished structure of social and cultural anthropology, which makes articulation possible with all the disciplines which shatter anthropological research into fragments

KEYWORDS: analysis of cultural productions, analysis of identity processes, structural-dynamic approach, research by objectives, construction of research instruments, integrative theorization.
\end{abstract}

BASTOS, José Gabriel Pereira (bjgp@fcsh.unl.pt) - Centro em Rede de Investigação em Antropologia, Faculdade de Ciências Sociais e Humanas da Universidade Nova de Lisboa (CRIA-FCSH/Nova); Associação Portuguesa de Psicanálise e Psicoterapia Analítica (APPPA), Portugal.

\title{
DA PSICOLOGIA SOCIAL E DA PSICANÁLISE À ANTROPOLOGIA (DÉCADA DE 70)
}

Cheguei à antropologia nos anos da revolução, numa escola em plena efervescência (ISCSP - Instituto Superior de Ciências Sociais e Políticas, 1975-77) e da antropologia foi tudo o que conheci na década de 70. Tinha obtido uma formação de base em psicologia social (Instituto Superior de Psicologia Aplicada - ISPA, 1964-68 e 1970-71), profundamente dececionante, na medida em que escotomizava o sofrimento humano e as suas dimensões libidinais e políticas. Sem mestres, procurei na teoria freudiana a superação do estilhaçamento e do reducionismo disciplinares, contrários aos meus objetivos integrativos. O convite do professor Sedas Nunes para ser um dos seus oito assistentes convidados no lançamento da primeira cadeira de Introdução às Ciências Sociais em Portugal (1971-72), um processo que a PIDE, no meu caso, interrompeu, tinha-me levado a um forte aprofundamento da teoria marxiana. Tinha-me assim embrenhado na pesquisa aprofundada de duas teorizações fundamentais, a marxiana e a freudiana, buscando a possibilidade de as transcender pela sua integração (J. Bastos e Soczka 1978). Tendo tido acesso a uma conferência em que o professor Eduardo Luís Cortesão apresentou os trabalhos de Ruth Benedict (2005 [1934]) e, sobretudo, de Margaret Mead (1935), entrei na antropologia para trabalhar a hipótese, que não foi dececionada, de que o inconsciente e a simbolização libidinal que lhe está associada se mostravam 
muito amplificados na cena sociocultural dos povos "primitivos", com a vantagem que o recalcado de dadas culturas constituía o ideal cultural de outras, ${ }^{1}$ de tal modo que, com a mediação analítica e teórica do antropólogo, as culturas se interpretavam entre si. Tratava-se de ultrapassar o método comparativo e de aceder ao método estrutural-dinâmico que, contra Lévi-Strauss (1958), o criador do estruturalismo estático, me propus construir.

\section{DA PSICANÁLISE À ANÁLISE DAS PRODUÇÕES CULTURAIS (DÉCADAS DE 70 E 80)}

Convidado, após o 25 de Abril, para integrar a renovação pedagógica tanto do ISPA (1975-80) como da Faculdade de Letras, utilizei como laboratório as minhas aulas de Introdução à Psicanálise, nesta Faculdade (1975-88), criando para mim próprio desafios teóricos e iniciando um processo radical de análise das produções culturais, em busca da teorização do processo criativo subjacente à renovação cultural. O meu desafio era claro: se Freud (1972a [1900], 1972b [1905], 1974a [1913], 1974b [1927], 1974c [1930], 1975 [1937], 1976 [1907], 1977 [1905], 1995 [1895]) tivesse razão, então todas as produções culturais ("arcaicas" ou "modernas") eram suscetíveis de uma análise que designei desde logo como estrutural-dinâmica, pelas razões que se seguem. Lá longe, em França, a redescoberta do estruturalismo russo (Propp 1965; Lotman e Escuela de Tartu 1979; Todorov 1970), o desenvolvimento de um estruturalismo estático, por Lévi-Strauss (1958, 1967 [1958], 1973, 1977) e a emergência da semiótica francesa (Greimas 1966) tinham criado um novo campo de problematizações na análise do texto literário, que se distanciava do freudo-marxismo, forte no pós-guerra, numa direção racionalista (formalista, cognitivista, não hermenêutica). Tratava-se de linhas de orientação que era necessário confrontar com a teorização freudiana, criticar, integrar quanto possível e superar. Até que ponto a psicanálise tinha meios de confrontar os estruturalismos com as suas áreas cegas e com as suas contradições? Até que ponto a dimensão dinâmica, típica da abordagem freudiana, permitia ir para além de abordagens estruturalistas, numa direção integrativa?

O aprofundamento da formação em semiótica e teoria do texto, bem como da articulação entre literatura e psicanálise, levaram-me então a propor (1981) uma tese de doutoramento intitulada Génese e Estrutura da Narratividade, que tomava estrategicamente a obra de Maupassant como estudo de caso, a realizar

1 Algo óbvio nas grandes dimensões organizadoras que, entre outras, são a sexualidade, a agressão, o narcisismo, a dominação masculina e a hierarquização social, como Ruth Benedict (2005 [1934]) e Margareth Mead (1935) intuíram, sem terem instrumentos teóricos para ultrapassar categorizações "temperamentais", que nada têm a ver com teorizações estrutural-dinâmicas dos processos de contraposição identitária. 
duas visitas de estudo (Paris, 1982 e 1984) para dialogar com os principais investigadores e docentes parisienses de literatura e psicanálise e a avançar para novas e mais complexas análises do modo de produção e da economia do texto literário (J. Bastos 1982b, 1983c, 2014c), mais interessado na investigação das infraestruturas e dos organizadores inconscientes da criação literária do que na "interpretação" dos textos ou na psicobiografia dos autores. Esse processo caminhou para o seu fim quando, depois de questionar diretamente Greimas (1966), num seminário de mestrado, apresentei em público críticas claras quanto ao modo como o fundador da semiótica francesa se aproveitara da teorização freudiana, sem mencionar a origem de dezenas de conceitos que utilizara na sua Sémantique structurale.

\section{À DESCOBERTA DA ANTROPOLOGIA "DISCIPLINADA"}

Quando me virei para a antropologia, seguia as expectativas de Freud, distanciando-me da clínica em busca da macroscopia permitida pelas produções culturais partilhadas e públicas de "povos primitivos". Buscava então estender a análise das produções culturais das áreas artísticas e literárias à área das instituições, processos, dinâmicas e relações socioculturais identitárias. ${ }^{2}$

Não compreendia então, e ainda hoje não compreendo, como é que a teoria da produção inconsciente da cultura, como formação de compromisso instável entre tensões libidinais, agressivas e narcísicas entre géneros, gerações, hierarquias e modos de relação interétnica, com derivação identitária, não foi estabelecida pelos antropólogos, tão mais favorável era a oportunidade da análise cultural (pública, comunitária) em relação à análise clínica (dual, suspeitada de "anormalidade"). Hoje apercebo-me de que os historicismos reconstrutivos (evolucionistas e difusionistas) e as abordagens sociológicas racionalistas não poderiam ter levado longe, de um ponto de vista teórico; que, na Europa, a antropologia colonial, tipicamente etnográfica, fora absorvida pelas suas finalidades pragmáticas e ideológicas, de afirmação implícita da supremacia racial, "civilizacional", dos "observadores" etnográficos e que estremecia perante a virtualidade de ser engolida pela abordagem psicanalítica, o que suscitava anticorpos mal fundamentados e escassamente elaborados; e que a teoria do

2 Para questões de método e teóricas, ver J. Bastos (1978b, 1983c, 1994, 2014c), J. Bastos e Ribeiro (2014). Para descobertas com implicações teóricas integrativas, ver J. Bastos (2012a, 2012b, 2014a). Para a teorização da análise das produções culturais, ver J. Bastos (1978c, 1988c, 1991), J. Bastos e Ribeiro (2014). Para a análise estrutural-dinâmica das produções culturais das áreas artísticas e literárias, ver J. Bastos (1978c, 1981a, 1981b, 1981c, 1982a, 1982b, 1982c, 1982d, 1983a, 1983b, 1984a, 1984b, 1984c, 1984d, 1984e, 1985a, 1985b, 1986, 1988a, 1988b, 1993, 1994, 1995a, 1996, 1998, 2006c, 2014c, 2014d); J. Bastos et al. (2001); Bastos, Ribeiro e Fox (2014). Sobre análises de instituições e de rituais, ver J. Bastos (1997b); S. Bastos e J. Bastos (1989, 1995, 1998a, 200 lb), J. Bastos e Costa (no prelo). 
relativismo cultural (que refutámos em J. Bastos 201 l), e o estrutural-funcionalismo, sem qualquer capacidade heurística, tinham tornado tabu o caminho para teorizações transculturais do modo de produção cultural (sua génese, função, economia, valor e sentido).

Desses anos, lembro-me que o desafio partia da obra de Lévi-Strauss, que se tornou o terceiro pilar da minha busca teórica, para rapidamente o contestar. No ISCSP desses anos, Lévi-Strauss era representado por José Carlos Gomes da Silva, recém-chegado de Bruxelas, que os alunos marxistas tentaram despedir, o que impedi ativamente. Não esqueço que o confrontei em aula com uma leitura alternativa das suas bilinas russas, utilizando a minha metodologia estrutural-dinâmica, que pretendia que fosse pós-lévi-straussiana, para demonstrar ganhos de heuristicidade. É fácil perceber que não gostou de se ver confrontado com uma alternativa tão elaborada, assente em dinâmicas triádicas e não em binarismos. Dos trabalhos escolares então apresentados e do esforço de teorização efetuado emergiram os primeiros artigos na área, na Análise Psicológica (J. Bastos 1978a, 1978b; J. Bastos e Soczka 1978) e na Colóquio-Letras (J. Bastos 1978c).

Data dessa época o encontro com o trabalho do antropólogo colombiano Reichel-Dolmatoff (1976 [1969]), que fizera uma descoberta com profundas implicações teóricas, por ele desperdiçadas, evidenciando a existência "tribal" de uma linguagem visual "geométrica" com significações libidinais evidentes, em concordância total com as descobertas freudianas, num artigo que de imediato fiz publicar na Análise Psicológica, seguido de uma apresentação crítica (J. Bastos 1978a), à espera de desenvolvimentos que desde logo me propus, mas que tiveram de esperar até ao final da década de 80 , por um espaço docente no território antropológico e pelos indispensáveis avanços metodológicos, implicando a criação de um instrumento de pesquisa suscetível de análise correlacional.

\section{DO ENSINO E DA INVESTIGAÇÃO EM PSICANÁLISE AO ENSINO E INVESTIGAÇÃO EM ANTROPOLOGIA SOCIAL E CULTURAL (DE 1987 EM DIANTE)}

Chegara a altura de mudar de rumo. Apoiado na minha licenciatura em Antropologia, na formação psicanalítica acumulada e no trabalho de investigação já publicado, apresentei candidatura à lecionação, no Departamento de Antropologia da Faculdade de Ciências Sociais e Humanas (FCSH) da Universidade Nova de Lisboa, das cadeiras de Antropologia e Psicanálise (I e II), então vacantes e em risco de abandono, por morte da minha ex-aluna, a Dr. ${ }^{a}$ Manuela Fazenda Martins. Era para mim quase uma missão defender essa área de pesquisa e ensino, tendo começado a lecioná-la em 1987-88. ${ }^{3}$ 
Esse espaço de ensino permitiu que me debruçasse, por um lado, sobre antropólogos pós-freudianos, como Róheim, Kardiner (trabalhando com Linton), Erikson e, mais tarde, Turner, Devereux, Gregor, Herdt (trabalhando com Stoller), Lidz e Lidz, Obeyesekere, Godelier e Juillerat (trabalhando com André Green), cujo entrosamento antropológico e potencial teorizante eram óbvios e, por outro lado, sobre o trabalho de investigadores que, próximos das conceptualizações e questões levantadas pela psicanálise, utilizavam instrumentos de pesquisa quantificados ou recorriam aos métodos matemáticos para chegar a modelos e correlações entre variáveis, com base em investigações replicáveis, como era o caso de Whiting e Child (1953), Whiting, Kluckhohn e Anthony (1966 [1958]), Stephens (1962), bem como Fromm e Maccoby (1970). ${ }^{4}$ Com estes autores, a antropologia passava da sua infância hermenêutica, ensaística, para relevantes voos científicos, enquadrados na antropologia psicológica, algo que parecia escapar à consciência disciplinar etnográfica, que permanecia pacatamente autossatisfeita com a antropologia sociológica, mantendo uma dicotomização sistemática interdisciplinar, a meu ver absurda, entre a dimensão psicológica e a dimensão sociológica, necessariamente articuladas, sendo a investigação dos modos e consequências dessa articulação que constituíam, no nível teórico, o desafio antropológico, por excelência, como bem vira Lévi-Strauss.

No ano seguinte (1988) abandonei a Faculdade de Letras e integrei dois departamentos da FCSH - Estudos Portugueses e Antropologia. No primeiro lecionei Introdução às Ciências da Cultura e também Literatura e Psicanálise, até 1991, concentrando-me então finalmente na antropologia e na minha tese de doutoramento, já em curso. Ainda em 1988 publiquei A Mulher, o Leite e a Cobra: Um Ensaio de Antropologia Pós-Racionalista e, em 1991, uma adenda a esse livro (em Maidens, Snakes and Dragons), no King's College London, concretizando a agregação com um relatório de cadeira em Antropologia e Psicanálise (J. Bastos 2000g) ${ }^{5}$ e preparando o futuro ensino de Antropologia do Simbólico, a que só acedi em 2005, ${ }^{6}$ apresentando um relatório de cadeira (J. Bastos 2002c) nessa área tão favorável à contribuição psicanalítica.

Em antropologia, a resistência à abordagem psicanalítica da cultura tinha-se exponenciado a partir da aliança entre biólogos e antropólogos disciplinares,

4 Para o primeiro conjunto de autores referidos, ver Róheim (1967 [1950], 1970 [1945]), Kardiner e Linton (1939), Kardiner et al. 1963 [1945]), Erikson (1963 [1950], 1968), Turner (1974 [1969]), Devereux (1977 [1970], 1980 [1960]), Devereux e Loeb (1985 [1943]), Gregor (1985), Herdt (1987, 1992 [1984]), Herdt e Stoller (1990), Lidz e Lidz (1989), Obeyesekere (1990), Godelier (1996, 2000 [1996]), Juillerat (1991, 1992), André Green (1977, 1992, 1995).

5 O único até hoje apresentado em Portugal. O reacionarismo teórico de biólogos e etnógrafos levou à retirada da cadeira do currículo de licenciatura da FCSH, única escola que a fizera lecionar, durante anos, como cadeira de opção bissemestral, muito concorrida.

6 A linha de antropologia do simbólico, estreitamente associada à análise das produções culturais e à teorização freudiana, foi sendo desenvolvida em J. Bastos (1988c, 1991, 1995a, 2000f, 2003a, 201 l, 2012d, 2014a, 2014c, 2014d), com relevantes descobertas teóricas. 
que tinham parado em leituras superficiais de Malinowski (1927) e Popper (1992 [1956], 1993 [1974]), e tanto mais defensivos quanto o meu ensino, aberto ao questionamento, ganhara fôlego e discípulos. Fui então forçado, através de uma reconversão curricular, a abandonar a cadeira inicial e a lecionar, durante seis anos (1990-96), exclusivamente, cadeiras de Psicologia (Psicologia Geral e Psicologia Social; Psicologia I e II), que esgotavam o meu tempo letivo, em claro bloqueio departamental do exercício da minha formação de antropólogo. No entanto, e dada a orientação integrativa que sempre assumi, em vez de isto constituir um obstáculo à progressão antropológica, obtive daí um estímulo que, orientado por uma metodologia guiada por objetivos, resultou num fluxo de criações metodológicas e descobertas teóricas, interessado que estava em participar nos debates-chave da antropologia (Ingold 1996).

\section{DO ENSINO À INVESTIGAÇÃO, CRIANDO INSTRUMENTOS DE PESQUISA ANTROPOLÓGICA SUSCETÍVEIS DE TRATAMENTO MATEMÁTICO (DÉCADA DE 90)}

Subalternizando a análise das produções culturais, segui então, a partir de 1990, três linhas de trabalho, em paralelo. Uma primeira, a linha etnográfica, realizada em casal, levou-me à comunidade hindu de Lisboa e, mais tarde, a dois meses de terreno na Índia (Diu e áreas vizinhas), no verão de 1990. Realizei, sobretudo, o levantamento das castas de Diu e seu mapeamento, o levantamento de linhagens de vandjás e de famílias de outras castas, o levantamento fotográfico dos mandirs de Diu e Fudam e a primeira aplicação não europeia de um instrumento de pesquisa criado por mim, aproveitando a lição de Reichel-Dolmatoff (1976 [1969]), que ele desperdiçara. Na minha contribuição para a escrita do terreno, enquadrei a pesquisa de uma forma teórica inovadora, a abordagem crise-analítica, antiessencialista, relacional e dinâmica (S. Bastos e J. Bastos 1998b, 2000b, 200 la, 200lb), que já então antecipava a proposta de uma antropologia dos processos identitários. Voltei ao trabalho de etnografia das relações interétnicas, em 2001 e em 2004, novamente em casal, junto dos portuguesia hindus de Londres e dos portugueses muçulmanos de Leicester (S. Bastos e J. Bastos 2002, 2005a, 2007) e, em 2005-06, com dois jovens investigadores, junto dos portugueses ciganos de Sintra (J. Bastos, Correia e Rodrigues 2007a, 2007b), cruzando os interesses da etnografia com os das relações interétnicas, dos processos identitários e do enquadramento identitário da ciganofobia, vista como um recurso da identidade "lusa", francamente vulnerabilizada pela descolonização e pelas crises económicas. ${ }^{7}$ Mais recentemente (em 2011 ) pesquisei o Círio de Nossa

7 Em ambos os casos, prolonguei a pesquisa etnográfica até à atualidade, aproveitando novas oportunidades. Sobre as relações interétnicas envolvendo a minoria dos portugueses ciganos [continua] 
Senhora do Rosário de Troia, em Setúbal, o que deu origem a um ensaio de distanciamento da etnografia descritiva, hegemónica, na direção de uma nova etnografia analítica, multidimensional e integrativa (J. Bastos e Costa, no prelo).

Uma segunda linha assentou na criação de instrumentos de pesquisa antropológica, articuláveis com problemas teóricos não acessíveis ao método etnográfico e/ou com os terrenos diretamente abordáveis, originando três instrumentos suscetíveis de alimentar o método comparativo, tanto lateral como longitudinal, dado serem replicáveis e dotados de flexibilidade adaptativa a problemas simbólicos e identitários e a contextos e níveis multidimensionais articulados diversos, comparáveis e integráveis.

Aproveitando o laboratório que me tinha sido oferecido com a cadeira de Psicologia Social, parti da deteção das representações de género por Anne-Marie Rocheblave-Spenlé (1964), em pequenas amostras de estudantes franceses e alemães, para avançar para um instrumento de pesquisa projetivo (o inquérito identitário multidimensional, IIM) e para propor à Fundação para a Ciência e a Tecnologia (FCT), em 1991, uma pesquisa, ousada pela sua dimensão, inovação e propósito científico, fundada no estudo estatístico, a partir de uma amostra representativa ( $\mathrm{N}=1043$ pessoas), do campo de representações sociais identitárias dos portugueses em contexto europeu, numa altura em que, recentemente (em 1985), se tinha avançado para a integração na União Europeia (UE, então Comunidade Económica Europeia). Tratava-se de uma questão antropológica que claramente escapa às limitações do método etnográfico, orientado para grupos locais e que, por isso, se tinha esgotado em ensaísmos contraditórios com elevado cunho ideológico, como aconteceu com a antropologia do Estado Novo. E de uma questão vexatória, porque entrava em contradição com o racionalismo antropológico, hegemónico, que, por isso mesmo, ameaçava não ser abordada cientificamente, com perdas heurísticas, a meu ver óbvias, dada a minha convicção de que os processos identitários constituem o principal organizador da diferenciação dos grupos sócio-históricos e da sua distanciação cultural, ${ }^{8}$ algo já anteriormente referenciado, sem teorização, por Lévi-Strauss (1958) e por Leach (1978 [1976]) e teorizado por Fredrik Barth (1998 [1969]), autores que deixaram claro que a "cultura" era uma variável subordinada aos processos de diferenciação identitária e não o contrário.

A minha tese de doutoramento infletia numa direção inesperada, mais de acordo com as minhas autoexigências científicas, mesmo que com o risco de

[continuação] e a ciganofobia em Portugal, ver J. Bastos (1997b, 2007, 2008, 2012c, 2012d, 2012e, 2013b); J. Bastos e S. Bastos (2000b, 2002), J. Bastos, Correia e Rodrigues (2007a, 2007b).

8 Sobre a pesquisa científica dos processos e estratégias de diferenciação identitária e sua teorização, ver J. Bastos (1995a, 1995b, 1997d, 2000f, 200 la, 2001b, 2002a, 2002b, 2002c, 2003b, 2003c, 2003d, 2005a, 2005b, 2006a, 2006b, 2010a, 2010b, 2014b); J. Bastos e S. Bastos (1999a, 1999b, 2000a, 2007); S. Bastos, J. Bastos e Soczka (2006); S. Bastos e J. Bastos (2000a, 2005a, 2005b, 2008). 
aumentar a resistência dos etnógrafos meus colegas, como realmente aconteceu. Os resultados tinham potencialidades heurísticas tão fortes que, defendida a tese (em fevereiro de 1996), avancei com um novo projeto para financiamento pela FCT (ainda em 1996), em que aprofundava e superava lacunas do anterior, investigando comparativamente as auto e heterorrepresentações regionais identitárias dos portugueses, com base numa amostra muito alargada: $\mathrm{N}=1800$, com 200 entrevistas em cada uma das nove regiões (J. Bastos e S. Bastos 1999b).

A tese foi publicada (J. Bastos 2000f), apresentada em Espanha num colóquio ibero-nórdico (J. Bastos 2002a), e nos Estados Unidos, em conferências na Califórnia - na UCLA e em Berkeley (J. Bastos 2003a, 2003b, 2003c, 2003d), bem como em duas aulas da cadeira lecionada em Berkeley por Stanley Brandes (em março de 2003). Entretanto, alunos tinham avançado para teses de licenciatura sustentadas por etnografia e pela aplicação local do meu inquérito (IIM), ${ }^{9}$ o que permitiu inferências teóricas notáveis que apareceram na tese mas também na parte final do Portugal Multicultural (J. Bastos e S. Bastos 1999a), e em conferências internacionais em Berkeley e Lisboa, explorando o caso cabo-verdiano (J. Bastos 2003c). ${ }^{10}$ A minha lição de agregação, apresentada no início de 2001 (e publicada em edição bilingue em 2013), ${ }^{11}$ ensaiava posicionar-se criticamente entre as orientações de dois colegas (ver João de Pina-Cabral 1991; João Leal 2000) e dar resposta às preocupações deste último, explorando as principais inferências teóricas na área dos processos identitários e desembocando na deteção de "leis" dos processos identitários, tais como decorrentes da pesquisa. Lançava, assim, as bases da fundação de uma antropologia dos processos identitários (J. Bastos $200 \mathrm{la}$ ), que concebo como a "pedra de fecho" da antropologia e da integração das ciências sociais, com pontos de apoio teórico na psicologia social e na psicanálise, dado ser a

9 Algumas dessas aplicações foram feitas nos seguintes contextos: cabo-verdianos de Lisboa e Cabo Verde (por Correia, em 1993); muçulmanos, em Rabat (por Pimentel, em 1993); hindus de Lisboa (por Bastos e Bastos, em 1994); açorianos, em São Miguel (por Godinho, em 1995); sardos, em Sassari (por Ribeiro, em 1996); espanhóis, em Córdoba (por Mourão, em 1997); muçulmanos, em Marrocos (por Pires, em 1997); angolanos, em Leiria (por Madeira, em 1999); emigrantes portugueses, em Paris (por Rodrigues, em 2003); húngaros em Budapeste (por A. C. Correia, em 2003); jovens sunitas de Lisboa (por Batoréu, em 2003); ucranianos em Portugal (por Barradas, em 2006). O estudo comparativo de várias destas pesquisas está incluído em J. Bastos e S. Bastos (1999a) e em J. Bastos (2000f).

10 Os dados regionais tiveram uma publicação mais difícil, resumindo-se até agora aos dados da região centro (beirões, ribatejanos e estremenhos), dos portuenses e dos alentejanos (J. Bastos 2005a, 2005 b, 2010b). Mas, tal como na tese, o que era realmente relevante não era a publicação dos dados mas as inferências teóricas que possibilitavam e a crítica dos ensaísmos identitários que exigiam, o que foi sendo feito, nomeadamente em S. Bastos e J. Bastos (2000a), na lição de agregação (J. Bastos 2001 a, 2013a) e na evidenciação dos limites dos métodos ensaísticos e comparativos (J. Bastos 2014e). 11 Ver J. Bastos (2001a, 2013a). 
única dimensão comum a todas elas, por isso mesmo recusada, da economia à ciência política, passando pela sociologia e pela linguística comunicacional.

Criei na mesma época e contexto um segundo instrumento de pesquisa ainda mais declaradamente projetivo, porque ainda mais incontrolável por processos cognitivos, decorrente das descobertas de Reichel-Dolmatoff (1973 [1968], 1976 [1969]) numa tribo da Amazónia, como mencionei anteriormente. Utilizei esse instrumento em amostras de hindus em Diu e em Lisboa (J. Bastos e S. Bastos 1999a; S. Bastos e J. Bastos 2000a, 2000b, 200 lc), mas só muito mais recentemente explorei em profundidade os dados obtidos com 150 estudantes universitários, de modo a demonstrar a dimensão transcultural do investimento inconsciente na cultura, baseada na deteção da função das imagens "abstratas" como mediação entre a representação inconsciente do corpo libidinal e a dimensão artística da cultura, e a introduzir o conceito de pele simbólica (J. Bastos 2012a, 2012b), pondo em xeque a generalidade da teoria do relativismo cultural, cujos pressupostos, claramente ideológicos, tinham bloqueado o desenvolvimento da ciência do homem (J. Bastos 2014a). ${ }^{12}$

Já num novo enquadramento estratégico, que passou pela criação de um Centro de Estudos de Migrações e Minorias Étnicas (o CEMME), em 2000, de modo a permitir institucionalizar e diversificar as pesquisas dos projetos FCT de 1993 e de 1996, a investigação dos processos identitários e das relações interétnicas, entre si associados, ganhou novas possibilidades de aprofundamento. Um projeto de fôlego (2003-2005), patrocinado pelo Observatório da Imigração, com o título "Filhos Diferentes de Deuses Diferentes"13 (S. Bastos e J. Bastos 2005b, 2008; J. Bastos 2010a, 2014b), permitiu avançar para o estudo comparativo de seis minorias étnicas residentes em Portugal, e foi para consolidar o projeto comparativo que criámos um terceiro instrumento de pesquisa, a escala de representações e atitudes interétnicas (ERAI), imanente ao próprio projeto e ao trabalho etnográfico em curso (entretanto conduzido por uma dezena de investigadores de terreno), associado ao levantamento da linguagem étnica em que se exprimiam e articulavam os diferentes eixos do campo estrutural-dinâmico - os eixos das tensões de género, das tensões intergeracionais, das tensões interétnicas e dos recursos religiosos com que tentavam organizar essas tensões. Partindo de 405 expressões retiradas dos terrenos e da bibliografia disponível, e anulando sobreposições, a equipa conseguiu a sua redução para 183, e uma análise fatorial selecionou 24, organizando quatro

12 Ideias apresentadas em conferências na FCSH (2011), no curso doutoral da Faculdade de Belas-Artes da Universidade do Porto (2011), bem como em Ghent (2012). Esta investigação estava enquadrada na disciplina que lecionei desde 2003, depois de ter apresentado para o concurso para professor associado um relatório de cadeira em Antropologia do Simbólico (J. Bastos 2002d).

13 Neste projeto levámos ao limite o que foi uma marca emblemática de todo o nosso percurso académico: a cooperação interdisciplinar integrativa, o trabalho de equipa na investigação e a publicação partilhada. 
fatores que explicavam 57\% da variância observada, um valor invulgarmente elevado, numa perspetiva explicativa. Os dois primeiros fatores evidenciavam dois modos de organização étnica, o primeiro centrado na organização das relações internas, primariamente no controlo masculino das relações de género, e declaradamente defensivo-agressivo (sikhs); um segundo, centrando-se na "acusação de racismo", colocava-se no polo oposto, nada informando sobre a organização interna dos grupos (cabo-verdianos), sendo que os ciganos cruzavam os dois fatores. A "acusação" emergia como o instrumento expressivo das relações interétnicas disfuncionais, tendendo a criar simetrias de acusação em relações assimétricas. Os dois últimos fatores evidenciavam estratégias positivas de justaposição religiosa ou de abertura à interetnicidade, com muito baixo nível de conflito (três comunidades de genealogia indiana, provenientes de Moçambique, os hindus, os ismaelitas e os sunitas). Tínhamos chegado a um primeiro nível de compreensão da diferenciação intercultural e das estratégias mobilizadas na interetnicidade (S. Bastos e J. Bastos 2005b; J. Bastos e S. Bastos 2010), bem como à deteção de diferentes tipos de família e de diferentes tipos de utilização do recurso religioso, com graus diferentes de afastamento e aproximação à ecologia cultural portuguesa (S. Bastos e J. Bastos 2007; Trovão e Bastos 2010), estudada na tese de doutoramento (Bastos 1995c, 2000f).

Os debates identitários in absentia, com as suas retóricas de acusações e simetrizações, permitiram em dois campos etnográficos, com os Portuguese Indians, de Londres, e com os portugueses sunitas, de Manchester (S. Bastos e J. Bastos 2002, 2005a e 2007), aprofundar e complexificar a análise destas estratégias identitárias de busca, recusa e inversão imaterial de hierarquizações identitárias entre comunidades imaginadas, funcionando como organizadores do fechamento dos grupos ao diálogo intercultural. E, em contexto migratório no terreno do grande adversário colonial, permitiram verificar como estas minorias de raiz indiana, tendo vivido em colónias portuguesas e britânicas, ao regressarem à Europa e, neste caso, encontrando-se face a face na Grã-Bretanha, mantêm debates identitários em que, para se atacarem e defenderem, se identificam com os ex-colonizadores, elogiando o seu e atacando o do outro, criando debates identitários a duas vozes mas com quatro referentes, argumentativamente fundados na seleção de valores e critérios convenientes para exprimir a superioridade identitária dos enunciantes e a inferioridade identitária atribuída ao adversário. Como Barth (1998 [1969]) encontrara ao referir-se aos processos de dicotomização sistemática entre grupos identitários, valores diferentes estabelecem fronteiras identitárias que separam grupos diferenciados, sem que impeçam o trânsito de pessoas através delas. Os valores de uns tendem a convergir com os defeitos que outros, mudando de critério, lhes atribuem (Leach 1978 [1976]), o que faz com que a atribuição de defeitos, e não apenas a afirmação de valores, constituam poderosos reforços das fronteiras identitárias mantidas de ambos os lados enquanto em interpenetração espacial. 


\section{DA ANTROPOLOGIA COLONIAL À INVESTIGAÇÃO DOS PROCESSOS IDENTITÁRIOS, DAS RELAÇÕES INTERÉTNICAS, DO RACISMO E DA XENOFOBIA}

Decorreu desta viragem estratégica a criação do CEMME, como referi, e a proposta da fundação de uma antropologia dos processos identitários que, no meu entendimento, deveria vir a constituir a pedra de fecho da transdisciplinaridade antropológica (J. Bastos 2002c). A colaboração interdisciplinar com o SociNova na criação, na FCSH, de um mestrado interdisciplinar em Migrações, Minorias Étnicas e Transnacionalismo, em 2002, o qual se manteve até à atualidade, e a integração numa rede de excelência europeia interdisciplinar, o IMISCOE (International Migrations, Integration and Social Cohesion in Europe), com sede na Universidade de Amesterdão, inserido então no seu C7, um grupo de investigação sobre processos identitários, relações interétnicas, discriminação, racismo e xenofobia, veio reafirmar a exigência da interdisciplinaridade e da integração transdisciplinar (J. Bastos 2010a; J. Bastos et al. 2006; S. Bastos e J. Bastos 2008; J. Bastos e S. Bastos 2010).

A abordagem estrutural-dinâmica que vínhamos propondo (J. Bastos 1997a, 1997c) permitiu selecionar seis eixos de observação (as relações de género, as relações intergeracionais, as relações interétnicas e as relações com o polo transcendental das religiões, anteriores à luta de classes e aos projetos imperiais e coloniais e, por cima destas, as relações de classe e as relações internacionais, onde aqueles projetos se exercem) e pesquisar a economia das articulações entre esses eixos (S. Bastos e J. Bastos 2005b; J. Bastos 2010a), a que se associou a demonstração da estreita articulação inconsciente entre as identidades corporais (de género e intergeracionais) e as identidades étnicas e políticas (inter-regionais e inter-nacionais). Decorreu desta investigação a deteção de modelos de diferenciação sócio-histórica (J. Bastos 2010a; J. Bastos e S. Bastos 2010), defensivos e acusatórios, de agonismo interétnico bem como de modelos de integração diferenciada, fantasmáticos e relacionais, superadores dessa agonisticidade.

Entretanto, um novo projeto, financiado em concurso público pela Câmara Municipal de Sintra (2004-2005) permitiu aprofundar o estudo das relações interétnicas envolvendo os portugueses ciganos. Passámos então da tradicional pesquisa em bairros de realojamento e investigámos a situação da minoria em todo o concelho, levantando em simultâneo representações interétnicas dos técnicos e políticos municipais e dos seus munícipes ciganos. Desta investigação emergiu o conceito de ciganofobia, como modo hegemónico de expressão do racismo em Portugal, tornando os ciganos o "mau objeto" da identidade nacional, o que conduziu à passagem de uma postura analítica para uma postura de intervenção sobre as políticas de interetnicidade desenvolvidas pelas autoridades portuguesas (J. Bastos, Correia e Rodrigues 2007a; J. Bastos 2008, 
2010c, 2012c, 2013b), a qual, acima do nível etnográfico e do nível da interetnicidade, proporciona um novo laboratório de investigação sobre as estratégias do racismo subtil e institucional e sua negação política e cultural, mobilizadas para o reforço de uma identidade nacional fragilizada pela pobreza relativa e pela descolonização, isto é, pela humilhação na competição com as nações dominantes (EUA e países mais desenvolvidos da UE), bem como com as nações ex-colonizadas (destacadamente o Brasil e Angola).

\section{A CENTRALIDADE DOS PROCESSOS IDENTITÁRIOS NA ORGANIZAÇÃO DO MUNDO}

A abordagem multidimensional, relacional, processual-dinâmica, transdisciplinar e integrativa que vimos prosseguindo, através de terrenos e métodos muito diversificados, tem vindo a confirmar a centralidade dos processos identitários, encontrando em autores como Erik Erikson (1963 [1950]), Fredrik Barth (1998 [1969]), Henri Tajfel (1982 [1980]) e Thomas Scheff (1994) suportes teóricos que importa integrar e desenvolver.

Pelo nosso lado, chamámos a atenção para a linha teórica que liga estes autores a uma tradição antropológica que vai de Sumner (1959 [1906]) a Ruth Benedict (2005 [1934]) e a Leach (1978 [1976]), transformando processos de diferenciação cultural em processos de competição e superiorização identitária, com cunho agonístico ou depreciativo, que implicam a subalternização do conceito de cultura (um efeito e não uma causa), como bem viram antropólogos como Leach (1978 [1976]) e Barth (1998 [1969]), abrindo uma nova posição na história da antropologia.

Estes desenvolvimentos convidam à construção de uma antropologia teórica, fundada na deteção da dimensão delirante dos processos identitários e da construção das representações e instituições sociais, anteriormente referenciada por Marx (1975 [1844]), Freud (1972a [1900], 1972b [1905], 1974a [1913], 1974b [1927], 1974c [1930], 1975 [1937], 1976 [1907], 1977 [1905], 1995 [1895]), Durkheim (1985 [1912]) e Edgar Morin (1975 [1973]), e na análise das dinâmicas de diferenciação sócio-histórica que se apoiam na multiplicação de línguas, de religiões, de morais, de atividades artísticas e de mitos grupais e na fidelização emocionada a esses organizadores de diferenciações entre si articuladas, num sistema-mundo (Wallerstein 1974) tensionalmente diferenciado, lateralmente (espacialmente, entre países, regiões, etc.) e verticalmente (nas tensões assimétricas entre classes sociais, geracionais, géneros e formações interétnicas), de forma multidimensional, contraditória e instável.

No seu conjunto, o trabalho até agora realizado assenta (1) na crítica do racionalismo, do estilhaçamento disciplinar das ciências do homem e dos seus impasses e negações cognitivas; (2) na atenção dada à análise das produções culturais; (3) na pesquisa orientada para uma reavaliação pós-freudiana 
dos processos simbólicos e identitários e da dimensão delirante da cultura; (4) numa abordagem integrativa, estrutural-dinâmica, pós-racionalista, que viabilize a emergência da Antropologia Teórica e a análise das contradições civilizacionais, materializadas no sofrimento socialmente provocado, entrevisto por Freud; (5) na construção de instrumentos de pesquisa, suscetíveis de tratamento matemático e de replicação, que permitam passar da descrição, tipicamente ensaística, à comparação lateral e longitudinal, cientificamente controlada, reabrindo o campo da cientificidade para as ciências antropológicas; (6) numa insistência estratégica na pesquisa multidimensional sobre os portugueses, suas relações internacionais, regionais, de género e relações interétnicas, com as suas minorias, ex-colonizados e imigrantes, na deteção do mito que articula as relações de género com as pretensões de uma excecionalidade identitária no tratamento com os seus outros, sustentando a sua ecologia identitária e as suas estratégias de diferenciação identitária num mundo competitivo em transformação acelerada; e, finalmente, (7) na investigação interventiva da economia identitária do racismo, exemplificado pela ciganofobia em Portugal.

Se quiserem questionar o que tudo isto tem a ver com a década de 70, é fácil de perceber: trata-se de pôr em confronto Freud e a antropologia psicanalítica, enquanto tese, com a contribuição racionalista do estruturalismo estático de Lévi-Strauss, enquanto antítese, à procura da superação de ambos os polos, através da construção de uma abordagem estrutural-dinâmica, centrada naquilo que não existe para Lévi-Strauss (1977), por confundir o cérebro com a mente e "odiar o Ego": a dinâmica sócio-histórica dos processos identitários, que são relacionais e multidimensionais. Como sabemos, Lévi-Strauss estava profundamente errado, desconhecia os efeitos da complexidade, e Antoine Danchin encarregou-se de lho evidenciar (Lévi-Strauss 1977: 209).

\section{BIBLIOGRAFIA}

BARTH, Fredrik, 1998 [1969], Ethnic Groups and Boundaries: The Social Organization of Culture Difference. Prospect Heights, IL, Waveland Press.

BASTOS, José, 1978a, recensão bibliográfica de Os Alucinógenos e o Mundo Simbólico, de Vera Penteado Coelho, Análise Psicológica, I (2): 110-111.

BASTOS, José Gabriel Pereira, 1978b, "Para uma metodologia estrutural-dinâmica de análise de textos literários”, Análise Psicológica, I (3): 33-49.

BASTOS, José Gabriel Pereira, 1978c, “'A bela e o monstro' na literatura oral portuguesa, uma abordagem estrutural-dinâmica”, Colóquio-Letras, 44: 46-59. 
BASTOS, José Gabriel Pereira, 1981a, “A rato-análise de Laborit-ório’ - sobre 'Mon oncle d'Amérique', de Alain Resnais”, JL - Jornal de Letras, Artes e Ideias, n. ${ }^{\circ} 2$, Lisboa, março: 31.

BASTOS, José Gabriel Pereira, 1981b, "Trabalhar sobre o corpo e sobre a escrita”, JL - Jornal de Letras, Artes e Ideias, n. ${ }^{\circ}$ 6, maio: 10-1 1 (republicado em João Vieira - 25 Anos de Trabalho: 1959-84, org. Julião Sarmento, Lisboa, \& ETC, 1985, 39-46).

BASTOS, José Gabriel Pereira, 1981c, "O circo europeu”, em Jerry Lewis, catálogo. Lisboa, Cinemateca Nacional, 45-48.

BASTOS, José Gabriel Pereira, 1982a, "Cinco passos em torno do desespero”, JL - Jornal de Letras, Artes e Ideias, n. ${ }^{\circ}$ 26, fevereiro: 17.

BASTOS, José Gabriel Pereira, 1982b, "Eldorados à portuguesa: o ouro e as suas vicissitudes em O Espólio do Senhor Cipriano, de Júlio Diniz”, em Eldorado. Lisboa e Porto, Quatro Elementos Editores, 82-96.

BASTOS, José Gabriel Pereira, 1982c, “To be or not to be, with Hitch, Guilty, Spellbound, Young and Innocent”, JL - Jornal de Letras, Artes e Ideias, n. ${ }^{\circ} 29$, abril.

BASTOS, José Gabriel Pereira, 1982d, "Silvestre: a virgem-mãe ou homem dividido vale por todos", JL - Jornal de Letras, Artes e Ideias, n. ${ }^{\circ}$ 33, maio: 27.

BASTOS, José Gabriel Pereira, 1983a, "A escrita do Deus", em Ilhas, catálogo da exposição de Ana Isabel Rodrigues. Lisboa, Sociedade Nacional de Belas-Artes.

BASTOS, José Gabriel Pereira, 1983b, "A estrangeira”, JL-Jornal de Letras, Artes e Ideias, n. 53, março.

BASTOS, José Gabriel Pereira, 1983c, "Entre le plaisir et l'action il y a place pour...: essai d'analyse structurale-dynamique de 'Ce cochon de Morin', de Guy de Maupassant", Ariane: Revue d'études littéraires françaises, 2: 131-220.

BASTOS, José Gabriel Pereira, 1984a, “Ninguém responde a Franz Kafka: 'Carta ao pai’, uma cartografia do naufrágio familiar", Plural, 4: 56-57.

BASTOS, José Gabriel Pereira, 1984b, “(h)ERO(i)S - de incerta viagem: sobreviventes”, em Heróis, catálogo da exposição de Ana Isabel Rodrigues, Alberto José Caetano e Carlos Nogueira. Lisboa, Galeria Quadrum.

BASTOS, José Gabriel Pereira, 1984c, “Sobreviventes: cartografia de uma viagem começada”, em Sobreviventes, catálogo da exposição de Ana Isabel Rodrigues, Lisboa, Galeria Cómicos.

BASTOS, José Gabriel Pereira, 1984d, "Pinter: do teatro do absurdo ao pós-modernismo: “Traições”, em “Traições”, de Harold Pinter, programa. Lisboa, Quarteto/Teatro de Actor.

BASTOS, José Gabriel Pereira, 1984e, "Nada é apenas o nome que lhe damos", apresentação do Álbum 'Kodak', de João Vieira, sobre poema de Herberto Helder. Lisboa, Galeria Altamira, junho.

BASTOS, José Gabriel Pereira, 1985a, "Ana: as águas, o leite e o sangue”, JL - Jornal de Letras, Artes e Ideias, n. ${ }^{\circ}$ 149, maio: 9-10 (republicado em António Reis e Margarida Cordeiro: A Poesia da Terra, Faro, Cineclube de Faro, 1997, 217-219).

BASTOS, José Gabriel Pereira, 1985b, “Sauve qui peut (la vie): entre o fantasma da política e a política do fantasma”, em Jean-Luc Godard, catálogo. Lisboa, Cinemateca Nacional, 176-198.

BASTOS, José Gabriel Pereira, 1986, “Metamorfoses”, em Metamorfoses, catálogo da exposição de João Vieira. Porto, Galeria Zen.

BASTOS, José Gabriel Pereira, 1988a, “Cartographie d'un voyage entamé ('andante')”, em Lisbonne aujourd'hui, catálogo de exposição. Toulon, Musée de Toulon. 
BASTOS, José Gabriel Pereira, 1988b, “Diálogos de Lisboa”, em Diálogos de Lisboa (com Francisco d'Ollanda), catálogo da exposição de João Vieira. Lisboa, Galeria Barata.

BASTOS, José Gabriel Pereira, 1988c, A Mulher, o Leite e a Cobra: Ensaio de Antropologia Pós-Racionalista. Lisboa, Edições Rolim.

BASTOS, José Gabriel Pereira, 1991, "From the chaos and the void of symbols to the rainbow of symbolim: the spectral study of symbols", em C. Knight, I. Cardigos e J. Bastos, Maidens, Snakes and Dragons. Londres, King's College (CESIL Papers), 7 1-102.

BASTOS, José Gabriel Pereira, 1993, "No coração da cidade incendiada, caligrafias ébrias, orientais”, Silêncio chinês (sobre Camilo Pessanha), em catálogo da exposição de João Vieira. Lisboa, ruínas do Chiado (Eduardo Martins).

BASTOS, José Gabriel Pereira, 1994, "Dos desejos e memórias arcaicas do corpo à produção artística e literária como forma privilegiada da comunicação de inconsciente a inconsciente: uma viagem pelo interior da obra de Freud", em J.G.P. Bastos (org.), Sigmund Freud: Textos Essenciais sobre Literatura, Arte e Psicanálise. Mem Martins, Publicações Europa-América, 7-39.

BASTOS, José Gabriel Pereira, 1995a, "Da corte do Olimpo ao Olimpo da corte: a eterna disputa”, em Maria João Brilhante e João Perry (orgs.), A Disputa, de Marivaux, programa. Lisboa, Teatro Nacional D. Maria II e INATEL, 19-23.

BASTOS, José Gabriel Pereira, 1995b, “Portugal, minha Princesa’: contribuição para o estudo das representações sociais identitárias dos portugueses”, Ethnologia, n.s., 1-2: 142-162.

BASTOS, José Gabriel Pereira, 1995c, Portugal, Minha Princesa: Contribuição para Uma Antropologia Pós-Racionalista dos Processos Identitários e para o Estudo do Sistema de Representações Sociais Identitárias dos Portugueses. Lisboa, Faculdade de Ciências Sociais e Humanas da Universidade Nova de Lisboa, dissertação de doutoramento, 2 vols.

BASTOS, José Gabriel Pereira, 1996, “Da arte como monstro necessário”, em Bestiário, catálogo da exposição de João Vieira. Lisboa, Galeria Fernando Santos.

BASTOS, José Gabriel Pereira, 1997a, Investigação Estrutural-Dinâmica sobre a (Trans)Formação da Identidade de Lugar Num Grupo de Idosos em Situação de Translocação Heteronómica. Lisboa, CNIG, documento policopiado.

BASTOS, José Gabriel Pereira, 1997b, "O conceito de representação: uma abordagem antropo-psicanalítica”, Revista da Faculdade de Ciências Sociais e Humanas, 10: 51-75.

BASTOS, José Gabriel Pereira, 1997c, "Ciências/Humanidades - grandes temores ou clivagens perigosas? Contribuição para uma teoria crítica das ciências sociais e das suas teorias críticas e para a abertura de um espaço estrutural-dinâmico de criatividade antropológica", apresentado no congresso "Sociedade, Cultura e Política no Fim do Século: A Reinvenção da Teoria Crítica”, Centro de Estudos Sociais da Universidade de Coimbra. BASTOS, José Gabriel Pereira, 1997d, As Minorias Étnicas em Portugal: Dos Dados Oficiais às Pesquisas e Estimativas Não-Oficiais. Relatório Preliminar. Lisboa, Métris.

BASTOS, José Gabriel Pereira, 1998, "Ao contrário de Narciso: aparições, impermanência, intersecções", em Impermanência: Um Caminho para o Auto-conhecimento, catálogo da exposição de Regina Chulam. Lisboa, Casa Fernando Pessoa.

BASTOS, José Gabriel Pereira, 1999a, “Complexo de Édipo”, verbete, em Enciclopédia Verbo Luso-Brasileira de Cultura - Edição Século XXI, vol. IX. Lisboa, Editorial Verbo, 1214-1218. BASTOS, José Gabriel Pereira, 1999b, "Erotismo (PSIC)”, verbete, em Enciclopédia Verbo Luso-Brasileira de Cultura - Edição Século XXI, vol. X. Lisboa, Editorial Verbo, 612-614. 
BASTOS, José Gabriel Pereira, 1999c, "Freud, Sigmund”, verbete, em Enciclopédia Verbo Luso-Brasileira de Cultura - Edição Século XXI, vol. XII. Lisboa, Editorial Verbo, 991-994.

BASTOS, José Gabriel Pereira, 2000a, "Identificação", verbete, em Enciclopédia Verbo Luso-Brasileira de Cultura - Edição Século XXI, vol. XV. Lisboa, Editorial Verbo, 373-377.

BASTOS, José Gabriel Pereira, 2000b, "Identidade (PSIC)", verbete, em Enciclopédia Verbo Luso-Brasileira de Cultura - Edição Século XXI, vol. XV. Lisboa, Editorial Verbo, 369-372.

BASTOS, José Gabriel Pereira, 2000c, "Psicanálise", verbete, em Enciclopédia Verbo Luso-Brasileira de Cultura - Edição Século XXI, vol. XVI. Lisboa, Editorial Verbo.

BASTOS, José Gabriel Pereira, 2000d, "Inconsciente (PSIC)", verbete, em Enciclopédia Verbo Luso-Brasileira de Cultura - Edição Século XXI, vol. XV. Lisboa, Editorial Verbo, 744-754.

BASTOS, José Gabriel Pereira, 2000e, "Ideal do ego", verbete, em Enciclopédia Verbo Luso-Brasileira de Cultura - Edição Século XXI, vol. XV. Lisboa, Editorial Verbo.

BASTOS, José Gabriel Pereira, 2000f, Portugal Europeu: Estratégias Identitárias Inter-Nacionais dos Portugueses. Oeiras, Celta Editora.

BASTOS, José Gabriel Pereira, 2000g, "Antropologia e Psicanálise", relatório da cadeira. Lisboa, Faculdade de Ciências Sociais e Humanas da Universidade Nova de Lisboa, documento policopiado.

BASTOS, José Gabriel Pereira, 2001a, "Das tradições da 'psicologia étnica' nacionalista e da 'antropologia social' imperialista à construção de uma antropologia dos processos identitários: critérios, estratégias, primeiros resultados”, lição de agregação. Lisboa, Faculdade de Ciências Sociais e Humanas da Universidade Nova de Lisboa, documento policopiado.

BASTOS, José Gabriel Pereira, 2001b, “Da arte como monstro necessário ao artista-mito", em AAVV, João Vieira: Percursos, 1960-2001. Lisboa, ACD Edições, 70-71.

BASTOS, José Gabriel Pereira, 2002a, "Portugal in Europe: The inter-national identity strategies of the Portuguese”, em L. Beltrán, J. Maestro e L. Salo-Lee (orgs.), European Peripheries in Interaction: The Nordic Countries and the Iberian Peninsula. Alcala, Alcala University Press, 223-247.

BASTOS, José Gabriel Pereira (org.), 2002b, "Antropologia dos processos identitários", número temático, Ethnologia, n.s.: 12-14.

BASTOS, José Gabriel Pereira, 2002c, “'Eppur si muove’: nota introdutória a uma antropologia dos processos identitários”, Ethnologia, n. s., 12-14: 11-35.

BASTOS, José Gabriel Pereira, 2002d, Antropologia do Simbólico, relatório da cadeira. Lisboa, Faculdade de Ciências Sociais e Humanas da Universidade Nova de Lisboa, documento policopiado.

BASTOS, José Gabriel Pereira, 2003a, “The hidden meanings of culture, ethnicity and identity: Anthropology from a divergent point-of-view”, apresentado no ciclo de conferências "In search of hidden meanings: identity processes and strategies from a triple point-ofview", Institut of European Studies, University of California, Berkeley (5 de março), documento policopiado.

BASTOS, José Gabriel Pereira, 2003b, “'I'm better than we are'/‘you should be as we are': identity paradoxes and the hidden strategies of social identity at the international level, the Portuguese case", apresentado no ciclo de conferências "In search of hidden meanings: identity processes and strategies from a triple point-of-view", Institut of European Studies, University of California, Berkeley (7 de março), documento policopiado.

BASTOS, José Gabriel Pereira, 2003c, “'They are as we need to see them’: racism, exemplariness, porosity and denigration in inter-ethnic relations, the Cape-Vertian case”, 
apresentado no ciclo de conferências "In search of hidden meanings: identity processes and strategies from a triple point-of-view”, Institut of European Studies, University of California, Berkeley (14 de março), documento policopiado.

BASTOS, José Gabriel Pereira, 2003d, “'Our colonisers were better than yours': identity debates in Greater London", apresentado no ciclo de conferências "In search of hidden meanings: identity processes and strategies from a triple point-of-view", Institut of European Studies, University of California, Berkeley (19 de março), documento policopiado.

BASTOS, José Gabriel Pereira, 2005a, "Beirões, estremenhos e ribatejanos: encontros e desencontros identitários”, em Ricardo Vieira (org.), Pensar a Região de Leiria. Porto, Edições Afrontamento, 31-53.

BASTOS, José Gabriel Pereira, 2005b, "Os portuenses e os seus outros: representações sociais identitárias dos portuenses num contexto de competição identitária inter-regional", apresentado no ciclo de conferências "Identidade/Identidades", Porto, Escola Superior Artística do Porto (7 de fevereiro), documento policopiado.

BASTOS, José Gabriel Pereira, 2006a, "CCape-Verdeans believe they are better than other Africans': approaching Cape-verdean identity dynamics in diasporic contexts”, apresentado no workshop "Leaving Lusophone countries: migrants (re)constructing their identities in destination countries", $11^{\text {th }}$ International Metropolis Conference, Lisboa, Fundação Calouste Gulbenkian (4 de outubro), disponível em < http://www.ceg.ul.pt/metropolis2006/WorkshopPresentations/Gulbenkian/JosePereiraBastos_metropolis2006.pdf > (última consulta em maio de 2014).

BASTOS, José Gabriel Pereira, 2006b, “'Eles são como nós precisamos que eles sejam para nos vermos como nos vemos': vicissitudes identitárias nas relações interétnicas", Revista da Faculdade de Ciências Sociais e Humanas, 18: 83-111.

BASTOS, José Gabriel Pereira, 2006c, "S-M-S ou a vertigem americana”, em Mariana Liz e Cláudia Maia (orgs.), Sonhos e Visões no Cinema, catálogo de textos, 5. ${ }^{\circ}$ Ciclo de Filmes da FCSH. Lisboa, Núcleo de Programação Cinematográfica, 123-126.

BASTOS, José Gabriel Pereira, 2007, "Que futuro tem Portugal para os portugueses ciganos?”, em M. Montenegro (org.), Ciganos e Cidadania(s). Setúbal, Instituto das Comunidades Educativas, 61-96.

BASTOS, José Gabriel Pereira, 2008, “O que se passa em Portugal com os portugueses ciganos?", Rediteia, 42: 49-53.

BASTOS, José, 2010a, "Different children of different gods: a structural-dynamic approach to using religion in processes of differentiated social insertion", em C. Westin et al., Identity Processes and Dynamics in Multiethnic Europe. Amesterdão, Amsterdam University Press, 279-311.

BASTOS, José Gabriel Pereira, 2010b, "Alentejo: região e identidade”, em AAVV, Jorge Crespo: Estudos em Homenagem, Castro Verde, 100Luz, 229-259.

BASTOS, José Gabriel Pereira, 2010c, "Sobre a questão cigana”, Expresso, n. ${ }^{\circ}$ 1978, 25 de setembro: 38-41.

BASTOS, José Gabriel Pereira, 2011, "Entre o corpo e a linguagem: a inscrição simbólica das tensões libidinais arcaicas no espaço artístico da modernidade 'abstracta", em M. Acciauolli e B. Marques (orgs.), Actas do Colóquio Arte e Erotismo. Lisboa, Instituto de História de Arte/Estudos de Arte Contemporânea, Faculdade de Ciências Sociais e Humanas da Universidade Nova de Lisboa, 337-387. 
BASTOS, José Gabriel Pereira (org.), 2012a, Portugueses Ciganos e Ciganofobia em Portugal. Lisboa, Edições Colibri.

BASTOS, José Gabriel Pereira, 2012b, "Portugueses ciganos e ciganofobia em Portugal: uma introdução", em J. G. P. Bastos (org.), Portugueses Ciganos e Ciganofobia em Portugal. Lisboa, Edições Colibri, 7-25.

BASTOS, José Gabriel Pereira, 2012c, "A questão cigana: portugueses ciganos e ciganofobia em Portugal”, em J.G.P. Bastos (org.), Portugueses Ciganos e Ciganofobia em Portugal. Lisboa, Edições Colibri, 337-389.

BASTOS, José Gabriel Pereira, 2012d, Contar Direito por Linhas Tortas: A Contoterapia Infantil - Para Uma Antropologia Pós-Racionalista III. Lisboa, Apenas Livros.

BASTOS, José Gabriel Pereira, 2012e, “Du corps au langage a travers des images géométriques: l'inscription symbolique des tensions libidinales archaïques dans l'espace artistique de la modernité abstraite", Gradiva, XIII (1), disponível em < http://www.ufr-anglais. univ-paris7.fr/GRADIVA/13-1/Jose_Gabriel_Pereira-Bastos-3.pdf > (última consulta em maio de 2014).

BASTOS, José Gabriel Pereira, 2013a, Para Uma Antropologia dos Processos Identitários: Critérios, Estratégias, Primeiros Resultados / Towards an Anthropology of Identity Processes: Criteria, Strategies, First Results. Lisboa, Edições Colibri e FCSH/UNL, edição bilingue.

BASTOS, José Gabriel Pereira, 2013b, "Reflexões sobre a questão cigana em Portugal”, em M. M. Mendes e Olga Magano (orgs.), Ciganos Portugueses: Olhares Plurais e Novos Desafios Numa Sociedade em Transição. Lisboa, Editora Mundos Sociais, 123-131.

BASTOS, José Gabriel Pereira, 2014a, "Enlarging and testing the concept of unconscious: the analysis of cultural productions", em C. Pracana (org.), Proceedings of the InPACT International Psychological Applications Conference and Trends, Porto 2014. Lisboa, World Institute for Advanced Research and Science, 14-18.

BASTOS, José Gabriel Pereira, 2014b, "Da etnografia colonial à análise estrutural-dinâmica de um campo de relações inter-étnicas”, em M. Santos et al. (orgs.), Caminhos da Migração: Memória, Integração e Conflitos. Rio de Janeiro, Léo Christiano Editorial, 135-153.

BASTOS, José Gabriel Pereira, 2014c, "Literary fights and world discourses in 'Lutteurs', by René Char”, em J. G. P. Bastos, D. C. Ribeiro e E. Fox (orgs.), Analyses of Cultural Productions. Papers of the 30th Conference of Psyart - Porto, 2013. Porto, i2ADS (Instituto de Investigação em Arte, Design e Sociedade), Faculdade de Belas-Artes da Universidade do Porto, 57-69.

BASTOS, José Gabriel Pereira, 2014d, "Nymphomaniac I and II: a Freudian narrative?", apresentado na 31 th Internacional Conference of Psyart, Madrid, documento policopiado.

BASTOS, José Gabriel Pereira, 2014e, "São os portugueses femininos e infantis, como afirmam ser, nos antípodas dos norte-europeus? Contribuição para a história identitária de um 'país invulgar'", em Atas do Congresso Arte \& Discursos: Dos Factos aos Relatos Construídos por Estrangeiros acerca de Portugal. Lisboa, Faculdade de Ciências Sociais e Humanas da Universidade Nova de Lisboa.

BASTOS, José Gabriel Pereira, et al., 2001, O Sintoma Big Brother. Lisboa, Publicações Terraço.

BASTOS, José Gabriel Pereira, et al., 2006, "Identity, representation, interethnic relations and discrimination”, em R. Penninx, M. Berger e K. Kraal (orgs.), The Dynamics of Migration and Settlement in Europe: A State of the Art. Amesterdão, Amsterdam University Press, 201-232. 
BASTOS, José Gabriel Pereira, e Susana Pereira BASTOS, 1999a, Portugal Multicultural: Situação e Estratégias Identitárias das Minorias Étnicas. Lisboa, Fim de Século.

BASTOS, José Gabriel Pereira, e Susana Pereira BASTOS, 1999b, Portugal Regional: Contribuição para o Estudo das Representações e das Estratégias Inter-regionais Identitárias dos Portugueses, relatório de investigação do projeto "Portugal Plural”, vol. 1. Lisboa, FCSH/UNL, documento policopiado.

BASTOS, José Gabriel Pereira, e Susana Pereira BASTOS, 2000a, “Quanto mais modesto mais português’: contribuição para o reequacionamento da antropologia urbana à luz de uma antropologia dos processos identitários", Ethnologia, n. s., 9-11: 13-49.

BASTOS, José Gabriel Pereira, e Susana Pereira BASTOS, 2000b, "Gypsies, in Portugal, today”, em Kisebbségek Európában 2000/Minorities in Europe 2000. Pécs, Universidade de Pécs, 99-113.

BASTOS, José Gabriel Pereira, e Susana Pereira BASTOS, 2002, "Imigrantes, minorias étnicas e minorias nacionais em Portugal, hoje: da exclusão social e identitária ao multiculturalismo?", em AAVV, A Imigração em Portugal: Os Movimentos Humanos e Culturais em Portugal. Lisboa, SOS-Racismo, 272-288.

BASTOS, José Gabriel Pereira, e Susana Pereira BASTOS, 2007, "We are going to show people here, that we have a different way of life", apresentado no Symposium (Re)inventing a Lusophone Culture in UK, Metropolitan University (28 de junho), documento policopiado.

BASTOS, José, e Susana BASTOS, 2010, "What are we talking about when we talk about identity?, in C. Westin et al. (orgs.), Identity Processes and Dynamics in Multiethnic Europe, Amesterdão, Amsterdam University Press, 313-358.

BASTOS, José Gabriel Pereira, André Clareza CORREIA, e Elsa RODRIGUES, 2007a, Sintrenses Ciganos: Uma Abordagem Estrutural-Dinâmica. Sintra, Câmara Municipal de Sintra.

BASTOS, José Gabriel Pereira, André Clareza CORREIA, e Elsa RODRIGUES, 2007b, “'We are Portuguese, but we have a different law": constants and vicissitudes of a failed interethnic 'dialogue'", apresentado na Annual Conference of the Gypsy Lore Society (University of Manchester, 7-8 de setembro), documento policopiado.

BASTOS, José, e Lucinda Fernandes BASTOS, no prelo, "Muitos fios tecem a imaterialidade de um ritual: análise estrutural-dinâmica do Círio de Nossa Senhora do Rosário de Tróia, em Setúbal", Trabalhos de Arqueologia e Etnologia (TAE online), 53 (a disponibilizar em http://revistataeonline.weebly.com).

BASTOS, José Gabriel Pereira, e RIBEIRO, Diniz Cayolla, 2014, "Analysis of cultural productions", em J.G.P. Bastos, D.C. Ribeiro e E. Fox (orgs.), Analyses of Cultural Productions. Papers of the 30th Conference of Psyart - Porto, 2013. Porto, i2ADS (Instituto de Investigação em Arte, Design e Sociedade), Faculdade de Belas-Artes da Universidade do Porto, 5-18.

BASTOS, José Gabriel Pereira, Diniz Cayolla RIBEIRO, e Elizabeth FOX (orgs.), 2014, Analyses of Cultural Productions. Papers of the 30th Conference of Psyart-Porto, 2013. Porto, i2ADS (Instituto de Investigação em Arte, Design e Sociedade), Faculdade de Belas-Artes da Universidade do Porto.

BASTOS, José Gabriel Pereira, e Luís SOCZKA, 1978, "Análise estrutural-dinâmica de Tarzan of the Apes de Edgar Rice Burroughs I", Análise Psicológica, l (3): 51-72.

BASTOS, Susana Pereira, e José Gabriel Pereira BASTOS, 1989, "Reflexões sobre a patogenia de uma instituição pragmático-familialista”, Psicologia, VII (2): 205-215. 
BASTOS, Susana Pereira, e José Gabriel Pereira BASTOS, 1995, “Do corpo ao cosmos: contributo para o estudo projectivo das representações simbólico-identitárias dos hindus-gujaratis residentes em Lisboa", em Projecto de Investigação "Ser Português em Portugal": Relatório Final, vol. 3. Lisboa, Faculdade de Ciências Sociais e Humanas, documento policopiado.

BASTOS, Susana Pereira, e José Gabriel Pereira BASTOS, 1998a, "Ideal e degradação, heteronomia e familialismo: duas investigações sobre a 'gestão racional' das margens sociais”, Revista da Faculdade de Ciências Sociais e Humanas, 11: 307-326.

BASTOS, Susana Pereira, e José Gabriel Pereira BASTOS, 1998b, "O trabalho de terreno como crise-análise intercultural: uma reflexão polifónica sobre as vicissitudes da pesquisa antropológica, em casal, no sul do Saurasthra”, Ethnologia, 6-8: 307-326.

BASTOS, Susana Pereira, e José Gabriel Pereira BASTOS, 2000a, “'To meet the other is, in fact, to meet him again': contribution to a structural-dynamic approach to the inter-ethnic relation in an urban context", Ethnologia, n. s., 9-11: 121-153.

BASTOS, Susana Trovão Pereira, e J. Gabriel Pereira BASTOS, 2000b, “Diu, Mozambique et Lisbonne: Histoire sociale et stratégies identitaires dans la diaspora des hindous-gujaratis", Lusotopie, 2000: 399-421.

BASTOS, Susana Pereira, e José Gabriel Pereira BASTOS, 2000c, "From a socioreligeous to a secret language: a plurimethodological contribution to the reformulation of the Hinduism concept", Estudos Orientais, VII: 151-177.

BASTOS, Susana Pereira, e José Gabriel Pereira BASTOS, 2001 a, De Moçambique a Portugal: Reinterpretações Identitárias do Hinduísmo em Viagem. Lisboa, Fundação Oriente.

BASTOS, Susana Pereira, e José Gabriel Pereira BASTOS, 200 lb, “A 'luta das representações' inter-regionais identitárias dos portugueses”, em L. Baptista (org.), Cidades e Metrópoles: Centralidades e Marginalidades. Oeiras, Celta Editora, 137-152.

BASTOS, Susana Pereira, e José Gabriel Pereira BASTOS, 2002, "De novo em viagem: as estratégias identitárias dos Portuguese Indians de Londres”, Ethnologia, n. s., 12-14: 127 $-161$.

BASTOS, Susana Pereira, e José Gabriel Pereira BASTOS, 2005a, “'Our colonisers were better than yours': identity debates in Greater London”, Journal of Ethnic and Migration Studies, 31 (1): 79-98.

BASTOS, Susana Pereira, e José Gabriel Pereira BASTOS (orgs.), 2005b, Filhos Diferentes de Deuses Diferentes: Usos da Religião em Estratégias de Inserção Social Diferenciada: Uma Abordagem Estrutural-Dinâmica. Lisboa, Observatório da Imigração.

BASTOS, Susana Pereira, e José Gabriel Pereira BASTOS, 2007, “'The blood of a Muslim is worthless, after all': identity debates between Portuguese and British Sunnis in Leicester", Lusotopie, 15 (1): 271-285.

BASTOS, Susana Pereira, e José Gabriel Pereira BASTOS, 2008, "Family dynamics, uses of religion and inter-ethnic relations within the Portuguese cultural ecology", em R. Grillo (org.), Family in Question: Immigrant and Ethnic Minorities in Multi-cultural Europe. Amesterdão: Amsterdam University Press, 135-163.

BASTOS, Susana Trovão, José Gabriel Pereira BASTOS, e Luís SOCZKA, 2006, "Das interetnicidades em processos de inserção social diferenciada às dinâmicas do sistema-mundo: uma abordagem estrutural-dinâmica", Revista da Faculdade de Ciências Sociais e Humanas, 18: 113-140.

BENEDICT, Ruth, 2005 [1934], Patterns of Culture. Boston e Nova Iorque, Houghton Mifflin. DEVEREUX, Georges, 1977 [1970], Essais d'ethnopsychiatrie générale. Paris, Gallimard. 
DEVEREUX, Georges, 1980 [1960], De l'angoisse à la méthode dans les sciences du comportement. Paris, Flammarion.

DEVEREUX, Georges, e Edwin M. LOEB, 1985 [1943], "Acculturation antagoniste", em G. Devereux, Éthnopsychanalyse complémentariste. Paris, Flammarion.

DURKHEIM, Emile, 1985 [1912], Les formes élémentaires de la vie religieuse. Paris, Presses Universitaires de France.

ERIKSON, Erik H., 1963 [1950], Childhood and Society: The Landmark Work on the Social Significance of Childhood. Middlesex e Vitoria, Penguin Books.

ERIKSON, Erik H., 1968, Identity: Youth and Crisis. Nova Iorque, W. W. Norton.

FREUD, Sigmund, 1972a [1900], "A interpretação dos sonhos", em Edição Standard Brasileira das Obras Psicológicas Completas de Sigmund Freud. Rio de Janeiro, Imago Editora, vols. IV e V, 1-663.

FREUD, Sigmund, 1972b [1905], "Três ensaios sobre a teoria da sexualidade", em Edição Standard Brasileira das Obras Psicológicas Completas de Sigmund Freud. Rio de Janeiro, Imago Editora, vol. VII, 129-250.

FREUD, Sigmund, 1974a [1913], "Totem e tabu”, em Edição Standard Brasileira das Obras Psicológicas Completas de Sigmund Freud. Rio de Janeiro, Imago Editora, vol. XIII, 17-191.

FREUD, Sigmund, 1974b [1927], "O futuro de uma ilusão", em Edição Standard Brasileira das Obras Psicológicas Completas de Sigmund Freud. Rio de Janeiro, Imago Editora, vol. XXI, 15-74.

FREUD, Sigmund, 1974c [1930], “O mal-estar na civilização”, em Edição Standard Brasileira das Obras Psicológicas Completas de Sigmund Freud. Rio de Janeiro, Imago Editora, vol. XXI, 81-171.

FREUD, Sigmund, 1975 [1937], "Construções em análise”, em Edição Standard Brasileira das Obras Psicológicas Completas de Sigmund Freud. Rio de Janeiro, Imago Editora, vol. XXIII, 291-301.

FREUD, Sigmund, 1976 [1907], "Psicopatologia da vida quotidiana", em Edição Standard Brasileira das Obras Psicológicas Completas de Sigmund Freud. Rio de Janeiro, Imago Editora, vol. VI, 19-340 (2. ${ }^{\text {a }}$ edição revista e aumentada).

FREUD, Sigmund, 1977 [1905], "Os chistes e a sua relação com o inconsciente", em Edição Standard Brasileira das Obras Psicológicas Completas de Sigmund Freud. Rio de Janeiro, Imago Editora, vol. VIII, 21-272.

FREUD, Sigmund, 1995 [1895], "Rascunho H, anexo à carta de 24 de janeiro de 1895", em Jeffrey M. Masson (org.), A Correspondência Completa de Sigmund Freud para Wilhelm Fliess - 1887-1904. Rio de Janeiro, Imago Editora, 108-1 13.

FROMM, Erich, e MACCOBY, Michael, 1970, Social Character in a Mexican Village. A Sociopsychanalytic Study. Englewood Cliffs, NJ, Prentice-Hall.

GODELIER, Maurice, 1996, "Meurtre du père ou sacrifice de la sexualité?", em M. Godelier, e J. Assoun (orgs.), Meurtre du père, sacrifice de la sexualité: Approches anthropologiques et psychanalytiques. Estrasburgo e Paris, Arcanes, 21-52.

GODELIER, Maurice, 2000 [1996], O Enigma da Dádiva. Lisboa, Edições 70.

GREEN, André, 1977, "Atome de parenté et relations oedipiennes", em C. Lévi-Strauss, L'identité. Paris, Bernard Grasset, 81-107.

GREEN, André, 1992, “The Oedipus complex as Muttercomplex”, em B. Juillerat (org.), Shooting the Sun: Ritual and Meaning in West Sepik. Washington e Londres, Smithsonian Institution Press, 144-172. 
GREEN, André, 1995, La causalité psychique: Entre nature et culture. Paris, Editions Odile Jacob. GREGOR, Thomas, 1985, Anxious Pleasures: The Sexual Lives of an Amazonian People, Chicago, IL, The University of Chicago Press.

GREIMAS, Algirdas Julien, 1966, Sémantique structurale: Recherche de méthode. Paris, Larousse. HERDT, Gilbert, 1987, The Sambia: Ritual and Gender in New Guinea. Nova Iorque, Holt, Rinehart \& Winston.

HERDT, Gilbert (org.), 1992 [1984], Homossexualidad Ritual en Melanesia. Madrid, Fundación Universidad-Empresa.

HERDT, Gilbert, e Robert J. STOLLER, 1990, Intimate Communications: Erotics and the Study of Culture. Nova Iorque, Columbia University Press.

INGOLD, Tim (org.), 1996, Key Debates in Anthropology. Londres e Nova Iorque, Routledge. JUILlERAT, Bernard, 1991, Oedipe chasseur: Une mythologie du sujet en Nouvelle-Guinée. Paris, Presses Universitaires de France.

JUILlERAT, Bernard (org.), 1992, Shooting the Sun: Ritual and Meaning in West Sepik. Washington e Londres, Smithsonian Institution Press.

KARDINER, Abram, e LINTON, Ralph, 1939, The Individual and His Society: The Psychodynamics of Social Organization. Nova Iorque, Columbia University Press.

KARDINER, Abram, et al., 1963 [1945], The Psychological Frontiers of Society. Nova Iorque, Columbia University Press.

LEACH, Edmund, 1978 [1976], Cultura e Comunicação: A Lógica pela Qual os Símbolos Estão Ligados. Rio de Janeiro, Jorge Zahar Editor.

LEAL, João, 2000, Etnografias Portuguesas (1870-1970): Cultura Popular e Identidade Nacional. Lisboa, Publicações Dom Quixote.

LÉVI-STRAUSS, Claude, 1958, Anthropologie structurale. Paris, Plon.

LÉVI-STRAUSS, Claude, 1967 [1958], “The story of Asdiwal”, em E. Leach (org.), The Structural Study of Myth and Totemism. Londres, Tavistock Publications, 1-47.

LÉVI-STRAUSS, Claude, 1973, Anthropologie structurale II. Paris, Plon.

LÉVI-STRAUSS, Claude, 1977, Lidentité. Paris, Bernard Grasset.

LIDZ, Theodore, e Ruth Wilmanns LIDZ, 1989, Oedipus in the Stone Age: A Psychoanalytic

Study of Masculinization in Papua New Guinea. Madison, International Universities Press.

LOTMAN, Iuri, e ESCUElA DE TARTU, 1979, Semiótica de la Cultura. Madrid, Ediciones Cátedra.

MALINOWSKI, Bronislaw, 1927, Sex and Repression in Savage Society. Londres, Kegan Paul, Trench, Trubner \& Co.

MARX, Karl, 1975 [1844], “Contribuição para a crítica da filosofia do direito de Hegel”, em

T. B. Bottomore (org.), Escritos da Juventude. Lisboa, Edições 70, 61-68.

MEAD, Margaret, 1935, Sex and Temperament in Three Primitive Societies. Nova Iorque, William Morrow \& Company.

MORIN, Edgar, 1975 [1973], O Paradigma Perdido: A Natureza Humana. Lisboa, Publicações Europa-América.

OBEYESEKERE, Gananath, 1990, The Work of Culture: Symbolic Transformation in Psychoanalysis and Anthropology. Chicago, The University of Chicago Press.

PINA-CABRAL, João de, 1991, Os Contextos da Antropologia. Lisboa, Editora Difel.

POPPER, Karl, 1992 [1956], O Realismo e o Objectivo da Ciência. Lisboa, Publicações Dom Quixote.

POPPER, Karl, 1993 [1974], Autobiografia Intelectual. São Paulo, Editora Cultrix. 
PROPP, Vladimir, 1965, Morphologie du Conte. Paris, Seuil.

REICHEL-DOLMATOFF, Gerardo, 1973 [1968], Desana: Le symbolisme universel des Indiens Tukano du Vaupés. Paris, Gallimard.

REICHEL-DOLMATOFF, Gerardo, 1976 [1969], "O contexto cultural de um alucinógeno aborígene - Banesteriopsis Caapi”, em Vera Penteado Coelho (org.), Os Alucinógenos e o Mundo Simbólico: O Uso dos Alucinógenos entre os Índios da América do Sul. São Paulo, EDU/EDUSP, 59-103 (republicado em Portugal em 1978, em Análise Psicológica, 1 (2): 87-102).

ROCHEBLAVE-SPENLÉ, Anne-Marie, 1964, Les roles masculins et féminins. Paris, Presses Universitaires de France.

RÓHEIM, Géza, 1967 [1950], Psychanalyse et anthropologie: Culture, Personnalité, Inconscient. Paris, Gallimard.

RÓHEIM, Géza, 1970 [1945], Héros phalliques et symboles maternels dans la mythologie australienne: Essai d'interprétation psychanalytique d'une culture archaïque. Paris, Gallimard.

SCHEFF, Thomas J., 1994, "Emotions and identity: a theory of ethnic nationalism", em Craig Calhoun (org.), Social Theory and the Politics of Identity. Oxford, Blackwell Publishers, pp. 277-303.

STEPHENS, William N., 1962, The Oedipus Complex: Cross-cultural Evidence. Nova Iorque, The Free Press of Glencoe.

SUMNER, William Graham, 1959 [1906], Folkways: A Study of the Sociological Importance of Usages, Manners, Customs, Mores, and Morals. Nova Iorque, Dover Publications.

TAJFEL, Henri, 1982 [1980], Grupos Humanos e Categorias Sociais. Lisboa, Livros Horizonte.

TODOROV, Tzvetan, 1970, As Estruturas Narrativas. São Paulo, Editora Perspectiva (2. ${ }^{\mathrm{a}}$ edição).

TROVÃO, Susana, e José Gabriel Pereira BASTOS, 2010, "Comparando relações de género, intergeracionais e familiares em populações imigrantes e minorias étnicas: debates "privados', denegação pública e outras mediações”, em Susana Trovão (org.), De Muitas e Variadas Partes ao Portugal do Século XXI. Lisboa, Edições Colibri e CEMME, 137-166.

TURNER, Victor W., 1974 [1969], O Processo Ritual: Estrutura e Anti-Estrutura. Petrópolis, Vozes.

WALLERSTEIN, Immanuel, 1974, The Modern World System. Nova Iorque, Academic Press.

WHITING, John W.M., e Irvin L. CHILD, 1953, Child Training and Personality: A Cross-Cultural Study. Yale, Yale University Press.

WHITING, John W.M., Richard KLUCKHOHN, e Albert ANTHONY, 1966 [1958], “The function of male initiation ceremonies at puberty", em Hendrik M. Ruitenbeek (org.), Psychoanalysis and Male Sexuality. New Haven, CT, College and University Press, 39-56. 